\title{
Clinical outcomes and prognostic factors of stereotactic body radiation therapy for intrahepatic cholangiocarcinoma
}

\author{
Ze-Tian Shen ${ }^{1}$, Han Zhou ${ }^{1}$, Ao-Mei Li ${ }^{1}$, Bing Li ${ }^{1}$, Jun-Shu Shen ${ }^{1}$ and Xi-Xu Zhu ${ }^{1}$ \\ ${ }^{1}$ Department of Radiation Oncology, Jinling Hospital, Medical School of Nanjing University, Nanjing, China \\ Correspondence to: Xi-Xu Zhu, email: simon_doctor@163.com \\ Keywords: intrahepatic cholangiocarcinoma, stereotactic body radiotherapy, CyberKnife, unresectable, Synchrony \\ Received: December 05, $2016 \quad$ Accepted: July 18, $2017 \quad$ Published: August 07, 2017 \\ Copyright: Shen et al. This is an open-access article distributed under the terms of the Creative Commons Attribution License 3.0 \\ (CC BY 3.0), which permits unrestricted use, distribution, and reproduction in any medium, provided the original author and source \\ are credited.
}

\section{ABSTRACT}

\begin{abstract}
Stereotactic body radiation therapy (SBRT) has been an emerging non-invasive treatment modality for patients with intrahepatic cholangiocarcinoma (ICC) when surgical treatment cannot be applied. The CyberKnife ${ }^{\circledR}$ is a SBRT system that allows for real-time tracking of the tumor. The purpose of this study was to evaluate the clinical outcomes and prognostic factors for ICC patients receiving this treatment. Twentyeight patients with ICC were enrolled in the present study. The median prescription dose was 45 Gy (range, 36-54 Gy), fractionated 3 to 5 times with a $70 \%$ to $92 \%$ isodose line. Local control, overall survival, progression-free survival and toxicity were studied. The median follow-up time was 16 months (3-42 months). Based on modified Response Evaluation and Criteria in Solid Tumors (mRECIST), response rate and disease control rate of SBRT in ICC were $46.4 \%(13 / 28)$ and $89.3 \%(25 / 28)$, respectively. Median overall survival was 15 months (95\% CI, 7.22-22.78). 1- and 2-years survival rates were $57.1 \%$ and $32.1 \%$, and 1- and 2- years Progression-free Survival rates were $\mathbf{5 0 . 0} \%$ and $\mathbf{2 1 . 4} \%$. Multivariate analysis revealed that number of lesions (solitary vs. multiple nodules), CA19-9 levels ( $\leq 37 \mathrm{U} / \mathrm{mL}$ vs. $37-600 />600$ ) and TNM stage (AJCC stage) were independent prognostic factors for ICC patients treated with SBRT. Toxicity was mostly transient and tolerable. No greater than grade 3 toxicity was observed. These results suggested that CyberKnife SBRT might be a good alternative treatment for unresectable ICC.
\end{abstract}

\section{INTRODUCTION}

Intrahepatic cholangiocarcinoma (ICC) is the second most common primary hepatic malignancy after hepatocellular carcinoma (HCC) [1], accounting for $10 \%-15 \%$ of primary liver cancers. Since 1973 , ICC has increased by $165 \%$ in 30 years in the USA [2]. China lacks reports in this regard, but the number of patients for the clinical diagnosis of ICC has been increasing every year.

For ICC, surgical resection has historically been considered the only curative option. However, only about one-third of patients present with resectable disease [3, 4]. Non-surgical options for patients with unresectable ICC include systemic chemotherapy [5], biliary drainage [6], external beam radiotherapy (EBRT) [7], transarterial chemoembolization (TACE) [8], and photodynamic therapy (PDT) [9-10]. However, ICC responds poorly to these therapies, so these palliative options are of limited benefit. Although EBRT is the most common local therapy utilized for patients without metastatic disease, the majority of patients eventually progress because of the low tolerance of the liver to radiation and the difficulty in localizing tumors as a result of organ motion [11].

As a new means of radiotherapy, CyberKnife avoids the errors caused by respiratory movement through synchronous respiratory tracking technology. By implanting gold fiducials in or around the tumors, tumor movement synchronized with respiratory motion can be truly tracked, more accurately giving the tumor higher doses, while reducing the dose to normal tissues [12-13]. With the advent of advanced imaging techniques and robotic image-guided radiation technologies, the 
CyberKnife SBRT achieves excellent conformality and significantly improves the therapeutic dose of localized liver lesions. Although SBRT has been used clinically for more than 10 years, especially in HCC [14-17], few studies were reported in ICC. Therefore, we retrospectively analyzed the efficacy, toxicity, and prognostic factors of SBRT for 28 cases of patients with primary ICC.

\section{RESULTS}

\section{Patients' characteristics}

Patients' demographics and baseline characteristics were displayed in Table 1. A total of 28 ICC patients (18 males and 10 females), all confirmed by pathologic diagnosis, were collected in this study. All 28 patients did not have distant metastases and ascites. Eight patients had previously received TACE treatment before CyberKnife SBRT while the remaining 20 patients did not receive any other treatments. Eight of the 28 patients had more than one liver lesion, in which 5 patients had two lesions and 3 patients had three lesions. Of the 28 ICC patients, 19 patients had concomitant liver diseases in this study, among which 13 patients had hepatitis B, 2 patients had hepatitis $\mathrm{C}$, and 6 patients had hepatolithiasis. Among patients with hepatitis $\mathrm{B}$ or $\mathrm{C}, 8$ patients had cirrhosis. In the present study, 20 patients had Child-Pugh A (A5:8, A6:12) classification and 8 patients had Child-Pugh B (B7:3, B8:2, B9:3) classification.

\section{Local control rate}

Of the 28 patients with unresectable ICC who underwent CyberKnife SBRT, three patients (3/28, 10.7\%) achieved a complete response (CR) and 10 patients (10/28, $35.7 \%$ ) achieved a partial response (PR) at the first followup, resulting in an objective response rate (RR) of $46.4 \%$. Stable disease (SD) was observed in 12 patients $(42.9 \%)$, with an overall disease control rate (DCR) of $89.3 \%$. Especially, the response rates and disease control rates in patients receiving a biological effective dose (BED) of $\geq 100$ Gy was higher than those receiving BED $<100$ Gy (response rates: $52.4 \%$ vs. $0 \%, P=0.023$; disease control rates: $100 \%$ vs. $57.1 \%, P=0.011$ ). The response and disease control rates in patients with solitary lesions were higher than those in patients with multiple nodules lesions $(60 \%$ vs. $12.5 \%$, $P=0.038 ; 100 \%$ vs. $62.5 \%, P=0.017$ ) (Table 2 ).

\section{Long-term survival and prognostic factors}

Among the 28 patients, the median follow-up time was 16 (3-42) months, and the median overall survival (OS) and progression-free survival (PFS) time were 15.0 months (95\% CI, 7.22-22.78) and 11.0 months (95\% CI, 1.93-20.08) respectively. Overall survival rate at
1 - and 2-years was $57.1 \%$ and $32.1 \%$, while 1 - and 2year Progression-free Survival (PFS) rates were $50.0 \%$ and $21.4 \%$ (Figure 1). The analysis of the prognostic factors was based on survival calculated from the start of CyberKnife SBRT. To further analyze the prognostic factors of ICC patients receiving CyberKnife SBRT, multivariate analysis was applied with 11 parameters, including Gender, Age, ECOG performance status, ChildPugh classification, Diameter, Number of lesions, Tumor location, Reason for inoperability, CA19-9, AJCC stage and TACE. As indicated in Table 3 , number of lesions (HR, 5.444(95\%CI, 1.446 20.491), $\mathrm{P}=0.012$ ), CA19-9 levels (HR, 0.018(95\%CI, 0.001 0.228), $\mathrm{P}=0.002)$ and TNM stage (HR, 2.096(95\%CI, 1.111 3.954), $\mathrm{P}=0.022$ ) were independent prognostic factors for ICC patients receiving CyberKnife SBRT. Patients with solitary nodules, CA19-9 $\leq 37 \mathrm{U} / \mathrm{mL}$ or early clinical stage had better overall survival $(P<0.05)$.

\section{Side effects}

The Common Toxicity Criteria Adverse Events (CTCAE 4.0) radiation injury-grading criterion was used to evaluate radiation injury in the present study. The main side effects of treatment include mild fatigue, anorexia, nausea, vomiting, mildly elevated liver enzymes, and bone marrow suppression (Table 4). Grade 1-2 anorexia was the most common toxicity and was developed in $42.8 \%$ of the patients. Of the 28 patients, the grade 3 toxicities included grade 3 gastrointestinal ulcers (antral ulcer confirmed by endoscopy), liver enzyme toxicity and bone marrow suppression. Toxicities greater than grade 3 were not observed. Six patients with central region lesions experienced serious gastrointestinal reaction, in which one patient experienced grade 3 vomiting and two experienced grade 2 nausea and anorexia respectively.

When the tumor size smaller than $5 \mathrm{~cm}$, toxicities greater than grade 1 were not observed in which two cases developed grade 1 fatigue and nausea. Toxicities greater than grade 1 were all observed in the tumor size larger than $5 \mathrm{~cm}$. Especially, when the tumor size larger than $10 \mathrm{~cm}$, it was easier to experience fatigue, anorexia and nausea. Classic Radiation induced liver disease (RILD) was not observed in the whole group of patients. Two patients developed non-classic RILD. After symptomatic treatment, the cases recovered smoothly. There was no treatment-related death.

\section{DISCUSSION}

Surgical resection has been considered a preferred treatment modality for long-term control of some early stage ICCs. However, most patients have lost the opportunity of operation at diagnosis. Although TACE [8] and radiofrequency ablation (RFA) [18] have been widely used in ICC, the special features of ICC (fibrosis, 
Table 1: Patient and treatment characteristics

\begin{tabular}{|c|c|}
\hline Characteristics & No. $(\%)$ or median [range] \\
\hline \multicolumn{2}{|l|}{ Gender } \\
\hline Male & $18(64.3)$ \\
\hline Female & $10(35.7)$ \\
\hline \multicolumn{2}{|l|}{ Age(years) } \\
\hline$\leq 60$ & 11(39.3) \\
\hline$>60$ & $17(60.7)$ \\
\hline \multicolumn{2}{|l|}{ ECOG performance status } \\
\hline 0 & $16(57.1)$ \\
\hline 1 & $10(35.7)$ \\
\hline 2 & $2(7.2)$ \\
\hline \multicolumn{2}{|l|}{ Liver disease (etiology) } \\
\hline Hepatitis B & $13(46.4)$ \\
\hline Hepatitis C & $2(7.1)$ \\
\hline Cirrhosis & $8(28.6)$ \\
\hline Hepatolithiasis & $6(21.4)$ \\
\hline Unknown & $9(32.1)$ \\
\hline \multicolumn{2}{|l|}{ Child-Pugh classification } \\
\hline A5 & $8(28.6)$ \\
\hline A6 & $12(42.9)$ \\
\hline B7 & $3(10.7)$ \\
\hline B8 & $2(7.1)$ \\
\hline B9 & $3(10.7)$ \\
\hline \multicolumn{2}{|l|}{ Diameter(cm) } \\
\hline$\leq 5$ & $6(21.4)$ \\
\hline $5-10$ & $15(53.6)$ \\
\hline$>10$ & $7(25.0)$ \\
\hline \multicolumn{2}{|l|}{ Number of lesions } \\
\hline Solitary & $20(71.4)$ \\
\hline Multiple nodules & $8(28.6)$ \\
\hline \multicolumn{2}{|l|}{ Tumor location } \\
\hline Peripheral ICC ${ }^{*}$ & $22(78.6)$ \\
\hline Central ICC & $6(21.4)$ \\
\hline \multicolumn{2}{|l|}{ Reason for inoperability } \\
\hline Medical comorbidity & 7 \\
\hline Surgically unresectable & 16 \\
\hline Advanced age & 5 \\
\hline
\end{tabular}

(Continued) 
CA19-9(U/mL)

$\leq 37$

$37-600$

$>600$

TACE

Yes

No

AJCC stage(7th)

II

III

IVA

$3(10.7)$

*ICC: intrahepatic cholangiocarcinoma.

lack of blood supply, and large tumor volume) limit their application. Currently, systematic chemotherapy with or without local treatment [5] is a common strategy for inoperable ICC, and radiation therapy [7] is one of the most important local treatments.

In recent years, several studies have been reported on conventional radiotherapy used to treat ICC. Given the small sample size and most studies involved other types of cholangiocarcinoma, the clinical benefits of radiotherapy in ICC remains uncertain. In general, the response rate of radiotherapy on biliary tract cancer is $40 \%-45 \%[7,19,20]$, which was due to the technical limitations. The efficacy of conventional radiotherapy, such as three-dimensional conformal radiotherapy and intensity-modulated radiation therapy, remains to be improved.

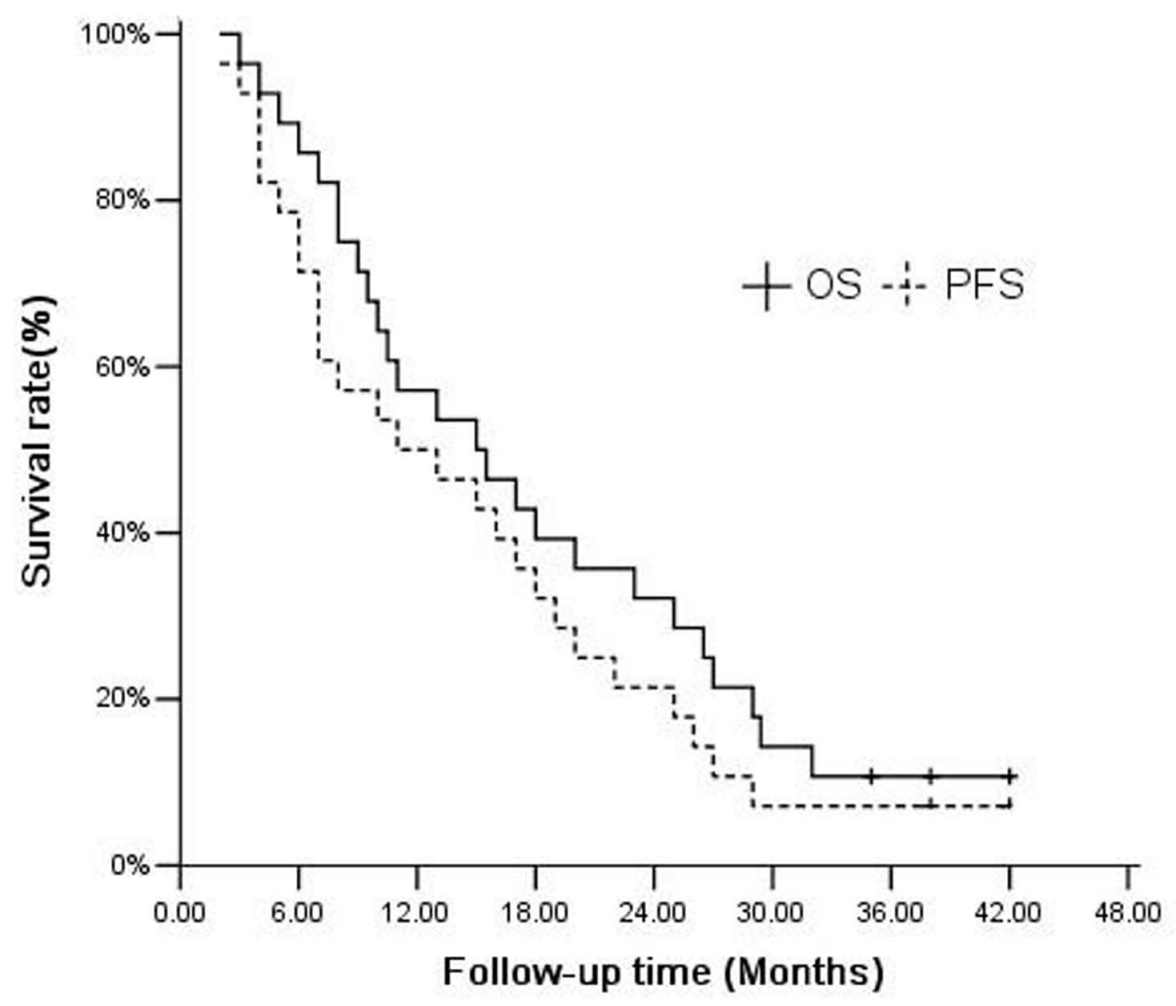

Figure 1: Kaplan-Meier curves for OS and PFS (n=28). 
Table 2: Local outcome of CyberKnife on 28 patients with locally advanced ICC [n (\%)]

\begin{tabular}{|c|c|c|c|c|c|c|c|}
\hline \multirow[t]{2}{*}{ Subgroup } & & \multicolumn{2}{|c|}{$\mathbf{R R}^{*}$} & \multirow[t]{2}{*}{$p$} & \multicolumn{2}{|c|}{$\mathbf{D C R}^{* *}$} & \multirow[t]{2}{*}{$p$} \\
\hline & & + & - & & + & - & \\
\hline & $\mathrm{n}$ & No. $(\%)$ & & & No. $(\%)$ & & \\
\hline Total & 28 & $46.4(13 / 28)$ & & & $89.3(25 / 28)$ & & \\
\hline \multicolumn{8}{|l|}{ Tumor types, n (\%) } \\
\hline Peripheral ICC & 22 & $50(11 / 22)$ & $50(11 / 22)$ & 0.655 & $95.5(21 / 22)$ & $4.5(1 / 22)$ & \multirow{2}{*}{0.107} \\
\hline Central ICC & 6 & $33.3(2 / 6)$ & $66.7(4 / 6)$ & & $66.7(4 / 6)$ & $33.3(2 / 6)$ & \\
\hline \multicolumn{8}{|l|}{ Diameter $(\mathrm{cm})$} \\
\hline$\leq 5, \mathrm{n}(\%)$ & 6 & $83.3(5 / 6)$ & $16.7(1 / 6)$ & 0.069 & $83.3(5 / 6)$ & $16.7(1 / 6)$ & \multirow{2}{*}{0.530} \\
\hline$>5, \mathrm{n}(\%)$ & 22 & $36.4(8 / 22)$ & $63.6(14 / 22)$ & & $90.9(20 / 22)$ & $9.1(2 / 22)$ & \\
\hline \multicolumn{8}{|l|}{$\begin{array}{l}\text { Intrahepatic lesions, } \\
\mathrm{n}(\%)\end{array}$} \\
\hline Solitary & 20 & $60(12 / 20)$ & $40(8 / 20)$ & 0.038 & $100(20 / 20)$ & $0(0 / 20)$ & \multirow{2}{*}{0.017} \\
\hline Multiple nodules & 8 & $12.5(1 / 8)$ & $87.5(7 / 8)$ & & $62.5(5 / 8)$ & $37.5(3 / 8)$ & \\
\hline \multicolumn{8}{|l|}{ TACE, n (\%) } \\
\hline Yes & 8 & $62.5(5 / 8)$ & $37.5(3 / 8)$ & 0.410 & $87.5(7 / 8)$ & $12.5(1 / 8)$ & \multirow{2}{*}{0.652} \\
\hline No & 20 & $40(8 / 20)$ & $60(12 / 20)$ & & $90(18 / 20)$ & $10(2 / 20)$ & \\
\hline \multicolumn{8}{|l|}{ BED } \\
\hline$\leq 100 \mathrm{~Gy}$ & 7 & $0(0 / 7)$ & $100(7 / 7)$ & 0.023 & $57.1(4 / 7)$ & $42.9(3 / 7)$ & \multirow{2}{*}{0.011} \\
\hline$>100 \mathrm{~Gy}$ & 21 & $52.4(11 / 21)$ & $47.6(10 / 21)$ & & $100(21 / 21)$ & $0(0 / 21)$ & \\
\hline
\end{tabular}

${ }^{*} \mathrm{RR}$ : Response rate $=$ Complete response $(\mathrm{CR})+$ Partial response $(\mathrm{PR})$.

${ }^{* *} \mathrm{DCR}$ : Disease control rate $=\mathrm{CR}+\mathrm{PR}+$ stable disease $(\mathrm{SD})$.

Table 3: Prognostic factors for overall survival of 28 patients

\begin{tabular}{|c|c|c|c|c|}
\hline \multirow[t]{2}{*}{ Variables } & \multirow[t]{2}{*}{$P$} & \multirow[t]{2}{*}{ HR } & \multicolumn{2}{|c|}{$95.0 \% \mathrm{CI}$ for $\mathrm{HR}$} \\
\hline & & & Lower & Upper \\
\hline Gender & 0.652 & 0.765 & 0.238 & 2.454 \\
\hline Age & 0.381 & 2.139 & 0.390 & 11.729 \\
\hline $\begin{array}{l}\text { ECOG performance } \\
\text { status }\end{array}$ & 0.150 & 0.453 & 0.154 & 1.331 \\
\hline $\begin{array}{l}\text { Child-Pugh } \\
\text { classification }\end{array}$ & 0.964 & 1.042 & 0.170 & 6.390 \\
\hline Diameter & 0.143 & 2.433 & 0.740 & 7.995 \\
\hline Number of lesions & 0.012 & 5.444 & 1.446 & 20.491 \\
\hline Tumor location & 0.495 & 1.059 & 0.898 & 1.250 \\
\hline $\begin{array}{l}\text { Reason for } \\
\text { inoperability }\end{array}$ & 0.389 & 0.999 & 0.998 & 1.001 \\
\hline CA19-9 & 0.002 & 0.018 & 0.001 & 0.228 \\
\hline AJCC stage & 0.022 & 2.096 & 1.111 & 3.954 \\
\hline TACE & 0.064 & 9.686 & 0.872 & 107.536 \\
\hline
\end{tabular}


Table 4: Side effects of 28 patents with ICC in the treatment of CyberKnife SBRT [n(\%)]

\begin{tabular}{|c|c|c|c|c|c|}
\hline \multirow[t]{2}{*}{ CTC 4.0 toxicity" } & 1 & 2 & 3 & 4 & 5 \\
\hline & n $(\%)$ & n (\%) & n (\%) & n (\%) & n (\%) \\
\hline Fatigue & $4(14.3 \%)$ & $3(10.7 \%)$ & $0(0)$ & $0(0)$ & $0(0)$ \\
\hline Lethargy & $5(17.9 \%)$ & $2(7.1 \%)$ & $0(0)$ & $0(0)$ & $0(0)$ \\
\hline Pleural effusion & $2(7.1 \%)$ & $1(3.6 \%)$ & $0(0)$ & $0(0)$ & $0(0)$ \\
\hline \multicolumn{6}{|l|}{ Gastrointestinal } \\
\hline Nausea & $8(28.6 \%)$ & $3(10.7 \%)$ & $1(3.6 \%)$ & $0(0)$ & $0(0)$ \\
\hline Anorexia & $\begin{array}{c}10 \\
(35.7 \%)\end{array}$ & $2(7.1 \%)$ & $2(7.1 \%)$ & $0(0)$ & $0(0)$ \\
\hline Vomiting & $5(17.9 \%)$ & $2(7.1 \%)$ & $1(3.6 \%)$ & $0(0)$ & $0(0)$ \\
\hline Duodenal ulcer & $2(7.1 \%)$ & $0(0)$ & $0(0)$ & $0(0)$ & $0(0)$ \\
\hline Gastric ulcer & $2(7.1 \%)$ & $1(3.6 \%)$ & $1(3.6 \%)$ & $0(0)$ & $0(0)$ \\
\hline \multicolumn{6}{|l|}{ Hepatic } \\
\hline ALT & $3(10.7 \%)$ & $4(14.3 \%)$ & $2(7.1 \%)$ & $0(0)$ & $0(0)$ \\
\hline AST & $5(17.9 \%)$ & $6(21.4 \%)$ & $1(3.6 \%)$ & $0(0)$ & $0(0)$ \\
\hline Albumin & $1(3.6 \%)$ & $6(21.4 \%)$ & $1(3.6 \%)$ & $0(0)$ & $0(0)$ \\
\hline ALP & $2(7.1 \%)$ & $3(10.7 \%)$ & $1(3.6 \%)$ & $0(0)$ & $0(0)$ \\
\hline Bilirubin & $2(7.1 \%)$ & $4(14.3 \%)$ & $2(7.1 \%)$ & $0(0)$ & $0(0)$ \\
\hline \multicolumn{6}{|l|}{ Bone marrow } \\
\hline WBC & $7(25 \%)$ & $3(10.7 \%)$ & $1(3.6 \%)$ & $0(0)$ & $0(0)$ \\
\hline $\mathrm{Hb}$ & $3(10.7 \%)$ & $2(7.1 \%)$ & $1(3.6 \%)$ & $0(0)$ & $0(0)$ \\
\hline PLT & $\begin{array}{c}10 \\
(35.7 \%)\end{array}$ & $2(7.1 \%)$ & $1(3.6 \%)$ & $0(0)$ & $0(0)$ \\
\hline
\end{tabular}

${ }^{*}$ CTC 4.0: The Common Toxicity Criteria Adverse Events (version 4.0).

The appearance of SBRT therapeutic modalities compensates for the deficiencies of conventional radiotherapy. Nowadays, SBRT is increasingly applied to inoperable liver cancer. However, reports of SBRT for treating liver tumors were mainly about primary hepatocellular carcinoma and liver metastases $[15,21$, 22], few reports were about ICC. Most of the studies were retrospective with small cohorts mixing ICC and HCC types simultaneously [23, 24], so the results of the studies could not completely reflect the therapeutic effect of ICC. Barney [25] reported the results of 10 patients with only advanced cholangiocarcinoma treated with SBRT; a total of 12 lesions, 6 cases of primary, and six cases of recurrence were reported, with a median dose of $55 \mathrm{~Gy}$ (45-60 Gy), median follow-up time of 14 months (2-26 months), local control rate of $100 \%$, six-month survival rate of $83 \%$, and 12 -month survival rate of $73 \%$. In this study, SBRT achieved good clinical effects for ICC, but the severe side effects (such as Grade 5 liver failure) limited its further clinical application.
The most comparable series to the present study is from Mahadevan et al [26]. They reported on 34 patients with 42 lesions containing 31 intrahepatic and 11 hilar lesions. The median SBRT dose was 30Gy in three fractions and the median follow-up was 38 months (range 8-71months). Their actuarial 1-year local control rate was $88 \%$. The median OS and PFS were 17 months and ten months. While in the present study, 1-year local control rate (89.3\%), median OS (15 months) and median PFS (11 months) were comparable with Mahadevan's study.

The local control rate was significantly higher than the previous reports, suggesting that the local control rate of SBRT for treating ICC was at a higher level, even for patients who had previously received TACE treatment. In this study, lesions greater than 5 and $10 \mathrm{~cm}$ accounted for $78.6 \%$ and $25 \%$, respectively, and the center of large tumor necrosis during follow up reduced efficiency. Affected by the age of patients, physical condition, extent, location of the lesion, and other factors, we only administered the palliative treatment dose. Our study found a higher rate of 
Table 5: Dosimetry index of the 28 patients during CyberKnife SBRT

\begin{tabular}{|c|c|c|c|}
\hline \multirow[t]{2}{*}{ Item } & \multicolumn{3}{|c|}{ Median (range) } \\
\hline & Total & $\leq 5 \mathrm{~cm}$ & $>5 \mathrm{~cm}$ \\
\hline Gross tumor volume (cc) & $267.4(43.4-1302.8)$ & $74.3(43.4-123.4)$ & $327.2(232.7-1302.8)$ \\
\hline Prescription dose (Gy) & $45(36-54)$ & $48(45-54)$ & $42(36-50)$ \\
\hline Dose per fraction (Gy) & $15(10-18)$ & $16(15-18)$ & $13(10-16)$ \\
\hline Conformity index (CI*) & $1.14(1.02-1.32)$ & $1.05(1.02-1.10)$ & $1.21(1.13-1.32)$ \\
\hline New conformity index $\left(\mathrm{nCI}^{* *}\right)$ & $1.23(1.12-1.45)$ & $1.16(1.12-1.24)$ & $1.27(1.24-1.45)$ \\
\hline Coverage $^{* * *}(\%)$ & $92(85-100)$ & $96(92-100)$ & $89(85-95)$ \\
\hline Number of beams (median) & $136(45-284)$ & $78(45-142)$ & $147(129-284)$ \\
\hline Prescription isodose line $(\%)$ & $78(72-90)$ & $85(82-90)$ & $76(72-84)$ \\
\hline
\end{tabular}

${ }^{*} \mathrm{CI}$ (Conformity Index): The ratio of the tissue volume that received the prescription isodose or more to the tumor volume receiving the prescription isodose or more.

${ }^{* *}$ nCI (New Conformity Index): The data of the CI multiplied by the ratio of the total tumor volume to the tumor volume receiving the prescription isodose or more.

${ }^{* * *}$ Coverage: The volume of the tumor that received greater than or equal to the prescribed dose divided by the total volume of the tumor times 100 .

Table 6: The standard of dose limitation in critical structures and its actual exposure dose

\begin{tabular}{|c|c|c|c|c|c|}
\hline \multirow{2}{*}{$\begin{array}{l}\text { Critical } \\
\text { structures }\end{array}$} & \multirow{2}{*}{$\begin{array}{c}\text { Total max dose } \\
(\text { Gy) }\end{array}$} & \multirow{2}{*}{$\begin{array}{c}\text { D33.3* (Gy) } \\
\text { Mean(range) }\end{array}$} & \multirow{2}{*}{$\begin{array}{c}\text { Max dose(Gy) per } \\
\text { fraction }\end{array}$} & \multicolumn{2}{|c|}{ Dose constraints $^{* *}$} \\
\hline & & & & Volume & Dose \\
\hline Stomach & $10.2(5.4 \sim 21.5)$ & - & $2.4(1.8 \sim 4.6)$ & Any point & 6 Gy per fraction \\
\hline Duodenum & $11.8(4.8 \sim 27.6)$ & - & $2.8(1.6 \sim 5.5)$ & Any point & 6 Gy per fraction \\
\hline Spinal cord & $4.8(3.6 \sim 11.2)$ & - & $2.1(1.0 \sim 3.6)$ & Any point & 5Gy per fraction \\
\hline Left kidney & - & $4.2(1.6 \sim 9.4)$ & $1.6(1.2 \sim 2.6)$ & $\begin{array}{c}<1 / 3 \text { of the total } \\
\text { volume }\end{array}$ & 4 Gy per fraction \\
\hline $\begin{array}{l}\text { Right } \\
\text { kidney }\end{array}$ & - & $5.7(3.6 \sim 17.2)$ & $2.6(1.5 \sim 3.7)$ & $\begin{array}{c}<1 / 3 \text { of the total } \\
\text { volume }\end{array}$ & 4 Gy per fraction \\
\hline
\end{tabular}

${ }^{*} \mathrm{D} 33.3=33.3$ percentage of Volume receiving the exposure dose.

** Dose constraints: Dose constraints for critical structures were taken 5 fractions as a standard.

local control and efficiency in the BED $\geq 100$ Gy group, suggesting that BED may be an important factor of SBRT, which was similar to previous reports [27]. Notably, there were no uniform standards for the total dose, treatment times, single dose, and interval of CyberKnife SBRT to treat inoperable ICC. All these factors require further study.

For the 28 patients enrolled in this study, the median survival time was 15.0 months. The one-year OS and PFS rate were $57.1 \%$ and $50.0 \%$, and the two-year OS and PFS rate were $32.1 \%$ and $21.4 \%$, respectively. These values were better than the data reported [2326]. Multivariate analysis showed that the main factors affecting the long-term survival of ICC patients receiving
SBRT were the number of lesions (solitary vs. multiple nodules), CA19-9 levels ( $\leq 37 \mathrm{U} / \mathrm{mL}$ vs. 37-600/>600) and TNM stage (AJCC stage). For patients with multiple nodules and late clinical stages, many surrounding normal tissues restrict the distribution of the dose line, resulting in the uneven distribution of the dose and dose cold spots. Meanwhile, the tumor's internal blood supply is worse based on ICC. High levels of necrosis and tumor tissue hypoxia lead to radiation tolerance, and high-dose radiation therapy is still very difficult to overcome. Moreover, more advanced stage of the disease often means being prone to distant metastasis, thereby making the prognosis worse. 
Given that liver tumors move with breathing, CyberKnife SBRT avoids the errors caused by respiratory movement through synchronous respiratory tracking technology. Considering the high single dose, we strictly limited the irradiated dose (stomach, duodenum, and kidney) of surrounding normal tissues. The main side effects of SBRT were mild fatigue, anorexia, nausea, vomiting, mild elevated liver enzymes, and bone marrow suppression, which could be improved and returned to normal after positive symptomatic treatment. After more than two years of observation, no greater than grade 3 long-term radiation-related toxicities was occurred, suggesting that the treatment was relatively safe.

In the latest $\mathrm{NCCN}$ guideline, systematic chemotherapy was also one option for the treatment of unresectable ICC. Median survival time for patients who undergo at least 4 cycles of chemotherapy (Gemcitabinebased combination regimens or 5-FU-based regimens) ranges from 6 to 14 months, with PFS time ranges from 2.3 to 8 months $[5,28]$. However, in the present study, the median OS and PFS time of ICC patients treated by CyberKnife SBRT were 15.0 months and 11.0 months, which were significantly higher than that reported in the chemotherapy series.

In conclusion, our findings demonstrated that SBRT for inoperable ICC could achieve a high local control rate and one- and two-year survival rates. The toxicity could be tolerated and adverse reactions greater than grade 3 were not seen. Future studies should further expand the sample size. Optimal radiation dose and fractionation for future SBRT treatment is also needed to be studied.

\section{MATERIALS AND METHODS}

\section{Ethics statement}

Patients treated with CyberKnife SBRT were carried out in strict accordance with the procedure approved by Ethic Committee of Jinling Hospital. Patients have provided their written informed consents to receive the CyberKnife SBRT and agreed with their records to be used in this study.

\section{General information}

From March 2009 to September 2012, 28 patients participated in a retrospective study at the CyberKnife center, Jinling Hospital. Patients were included based on the following criteria: (1) histologically proven diagnosis of ICC; (2) Patients were eligible for treatment if they had inoperable ICC according to more than two liver surgery experts; (3) Eastern Cooperative Oncology Group(ECOG) performance status of $\leq 2$; (3)Child-Pugh score $\leq 7$; (4) adequate hematology, including an absolute neutrophil count $>1.5 \times 10^{9} / \mathrm{L}$, a platelet count $>50 \times 10^{9} / \mathrm{L}$, renal function with creatinine level $<2.0 \mathrm{mg} / \mathrm{dl}$; (5) patients with no previous experience of radiotherapy; (6)patients not showing extrahepatic metastases; (7)the normal liver volume of more than 700 cc. All patients were treated with SBRT in Department of Radiation Oncology of Jinling Hospital and had signed a written informed consent for treatment. This study was approved by the institutional review board.

\section{Fiducial marker placement}

All 28 patients were treated using a CyberKnife SBRT system (Accuray, USA). All patients were treated via respiration synchronous tracking (Synchrony); and three to six markers (size of $6.0 \mathrm{~mm} \times 0.8 \mathrm{~mm}$ ) were implanted within or around the tumor using a CT-guided $19 \mathrm{G}$ needle. The minimum distance should be $>2 \mathrm{~cm}$, and the angle should be $>15^{\circ}$ between two markers. CT scan was performed to observe whether the markers were in their proper positions or to detect the presence of pneumothorax 2 hours after implantation. A CT scan was performed again at 7-10 days after implantation. In the process of liver puncture, three cases developed grade 2 complications with less than $30 \%$ pneumothorax who recovered within 2 days via suction through a fine-needle puncture. Eight cases developed grade 1complications, consisting mostly of transient increases in blood pressure, local pain and hemorrhage. No tumor seeding was detected while grade 1 hemorrhage through needle passage was common.

\section{Positioning and target delineation}

Patients were in the supine position with the body fixed with a vacuum pad. Spiral CT (Brilliace Big Bore 16 CT Philips Germany) scanning was conducted with a slice thickness of $1 \mathrm{~mm}$. Hepatic scanning consisted of three phases (arterial phase, venous phase, and equilibrium phase). Hepatic scans covered $15 \mathrm{~cm}$ above and below the lesions. In order to better delineate tumor volumes, a set of MRI of liver was arranged in all patients, hepatic or delayed phases of MRI were fused with the planning CT scan for contouring, other phase images of MRI were used as reference. The gross target volume (GTV) and PTV were determined according to the tumor volume. We added a $5 \mathrm{~mm}$ margin to the GTV to account for residual inaccuracy of Synchrony. The prescription dose was defined as $100 \%$ of the GTV dose. The total PTV dose was not less than $95 \%$ of the prescription dose.

In cases of multiple tumors, we have used one center for each tumor. The center located in the geometric center of the markers. But, the lesions were included based on the following criteria: 1.At least one marker was implanted within each lesion; 2.The distance between each lesion was not larger than $3 \mathrm{~cm}$; 3. 4D-CT was used to measure the position and motion of the lesions. One additional margin (1-2mm) was planned on the basis of the original PTV of one lesion for residual inaccuracy of Synchrony. 4. 
For multiple lesions, the total PTV dose was not less than $95 \%$ of the prescription dose. 5 . The irradiation dose of the normal liver should be in accordance with the criteria of dose constraints.

\section{Treatment mode and methods}

Before treatment, a respiratory monitoring device was used to detect the position of the infrared generator placed on the chest of the patient to create a dynamic respiratory rhythm. The $\mathrm{X}$-ray $\mathrm{kV}$ digital images were obtained at different time points during the respiratory cycle to obtain the dynamics model between the gold seed fiducial (tumor) position and respiratory rhythm. The respiratory model was used to guide the accelerator to track the lesions within the liver and administer the dynamic radiation. The prescription dose of lesions was 36-54 Gy (median dose, 45 Gy) in three to five divided doses. The SBRT doses was converted into normalized total dose (NTD) at a fraction size of 2 Gy (NTD2Gy) using the linear quadratic equation $(\mathrm{BED}=$ total dose $\times$ $(1+$ dose per fraction $/ \alpha / \beta), \alpha / \beta=10$ for early responding tissue, $\alpha / \beta=3$ for late responding tissue). The BED10 for SBRT ranges from 72 Gy to $124.8 \mathrm{~Gy}$ (median $85.5 \mathrm{~Gy}$ ). The dosimetry indexes of the 28 ICC patients are summarized in Table 5.

When the CyberKnife SBRT plan was designed, the single point maximum dose was used as the limit standard for serial organs, and the single maximum dose of part volume was used as the limit standard for parallel organs. Five fractions were used as the limit standard for single point dose. Since most of patients had 5 fractions, the limit standard for single dose was appropriately increased for those patients with less 5 fractions. The dose constraints of the normal liver (total liver minus cumulative GTV) were specified that a minimum volume of $700 \mathrm{ml}$ should receive a total dose less than $15 \mathrm{~Gy}$ in 3-5 fractions. The other normal tissues actual received doses and limit standards are shown in Table 6.

\section{Follow up and evaluation}

Abdominal enhanced CT scan or MRI was performed one month after SBRT completion. Patients were monitored every three months thereafter. Clinical monitoring was performed every day. The mRECIST [29] Criteria in Solid Tumors was used to evaluate treatment efficacy. Response rate $(\mathrm{RR})=$ Complete response $(\mathrm{CR})+$ Partial response (PR), whereas disease control rate $(\mathrm{DCR})=\mathrm{CR}+\mathrm{PR}+$ Stable disease $(\mathrm{SD})$. Overall survival (OS) and progression-free survival (PFS) were measured from the start of CyberKnife SBRT. Follow up was performed every three months for a total of three to 42 months, with a median follow up of 16 months. The final follow-up time was in September 2012.
The Common Toxicity Criteria Adverse Events (version 4.0) radiation injury-grading criterion was used to evaluate radiation injury. Radiation induced liver disease(RILD) was characterized by either (1) anicteric elevation in alkaline phosphatase(ALP) to greater than twice the upper normal level and nonmalignant ascites (classic RILD) or (2) elevation of transaminases to at least five times the upper limit of normal or pretreatment levels (non-classic RILD) within 4 months after completion of radiotherapy.

\section{Statistical analysis}

SPSS 15.0 statistical software was applied for data analysis. The Kaplan-Meier method was used to analyze PFS and OS. The log-rank method was used to test the significance compared with the survival curves. Multivariate analysis of survival was carried out with Cox's regression model. $\mathrm{P}$ values less than 0.05 were considered statistically significant.

\section{CONFLICTS OF INTEREST}

The authors have no conflicts of interest.

\section{REFERENCES}

1. Aljiffry M, Abdulelah A, Walsh M, Peltekian K, Alwayn I, Molinari M. Evidence-based approach to cholangiocarcinoma: a systematic review of the current literature. J Am Coll Surg. 2009; 208:134-47.

2. Shaib YH, Davila JA, McGlynn K, El-Serag HB. Rising incidence of intrahepatic cholangiocarcinoma in the United States: a true increase? J Hepatol. 2004; 40:472-77.

3. Burke EC, Jarnagin WR, Hochwald SN, Pisters PW, Fong Y, Blumgart LH. Hilar cholangiocarcinoma: patterns of spread, the importance of hepatic resection for curative operation, and a presurgical clinical staging system. Ann Surg. 1998; 228:385-94.

4. Jarnagin WR, Fong Y, DeMatteo RP, Gonen M, Burke EC, Bodniewicz BS, Youssef BA, Klimstra D, Blumgart LH. Staging, resectability, and outcome in 225 patients with hilar cholangiocarcinoma. Ann Surg. 2001; 234:507-17.

5. Hezel AF, Zhu AX. Systemic therapy for biliary tract cancers. Oncologist. 2008; 13:415-23.

6. Malhi H, Gores GJ. Cholangiocarcinoma: modern advances in understanding a deadly old disease. J Hepatol. 2006; 45:856-67.

7. Chen YX, Zeng ZC, Tang ZY, Fan J, Zhou J, Jiang W, Zeng MS, Tan YS. Determining the role of external beam radiotherapy in unresectable intrahepatic cholangiocarcinoma: a retrospective analysis of 84 patients. BMC Cancer. 2010; 10:492. 
8. Kim JH, Yoon HK, Sung KB, Ko GY, Gwon DI, Shin JH, Song HY. Transcatheter arterial chemoembolization or chemoinfusion for unresectable intrahepatic cholangiocarcinoma: clinical efficacy and factors influencing outcomes. Cancer. 2008; 113:1614-22.

9. Nanashima A, Isomoto $\mathrm{H}$, Abo $\mathrm{T}$, Nonaka $\mathrm{T}$, Morisaki $\mathrm{T}$, Arai J, Takagi K, Ohnita K, Shoji H, Urabe S, Senoo T, Murakami G, Nagayasu T. How to access photodynamic therapy for bile duct carcinoma. Ann Transl Med. 2014; 2:23.

10. Harewood GC, Baron TH, Rumalla A, Wang KK, Gores GJ, Stadheim LM, de Groen PC. Pilot study to assess patient outcomes following endoscopic application of photodynamic therapy for advanced cholangiocarcinoma. J Gastroenterol Hepatol. 2005; 20:415-20.

11. Crane CH, Macdonald KO, Vauthey JN, Yehuda P, Brown T, Curley S, Wong A, Delclos M, Charnsangavej C, Janjan NA. Limitations of conventional doses of chemoradiation for unresectable biliary cancer. Int J Radiat Oncol Biol Phys. 2002; 53:969-74.

12. Que J, Kuo HT, Lin LC, Lin KL, Lin CH, Lin YW, Yang CC. Clinical outcomes and prognostic factors of CyberKnife stereotactic body radiation therapy for unresectable hepatocellular carcinoma. BMC Cancer. 2016; 16:451.

13. Song JH, Kang KM, Choi HS, Jeong H, Ha IB, Lee JD, Kim HC, Jeong YY, Cho YJ, Lee SJ, Kim SH, Jang IS, Jeong BK. Comparing the clinical outcomes in stereotactic body radiotherapy for lung tumors between Ray-Tracing and Monte-Carlo algorithms. Oncotarget. 2016; 7:1904553. https://doi.org/10.18632/oncotarget.5992.

14. O'Connor JK, Trotter J, Davis GL, Dempster J, Klintmalm GB, Goldstein RM. Long-term outcomes of stereotactic body radiation therapy in the treatment of hepatocellular cancer as a bridge to transplantation. Liver Transpl. 2012; 18:949-54.

15. Dewas S, Bibault JE, Mirabel X, Fumagalli I, Kramar A, Jarraya H, Lacornerie T, Dewas-Vautravers C, Lartigau E. Prognostic factors affecting local control of hepatic tumors treated by Stereotactic Body Radiation Therapy. Radiat Oncol. 2012; 7:166.

16. Huang WY, Jen YM, Lee MS, Chang LP, Chen CM, Ko $\mathrm{KH}$, Lin KT, Lin JC, Chao HL, Lin CS, Su YF, Fan CY, Chang YW. Stereotactic body radiation therapy in recurrent hepatocellular carcinoma. Int J Radiat Oncol Biol Phys. 2012; 84:355-61.

17. Choi BO, Choi IB, Jang HS, Kang YN, Jang JS, Bae SH, Yoon SK, Chai GY, Kang KM. Stereotactic body radiation therapy with or without transarterial chemoembolization for patients with primary hepatocellular carcinoma: preliminary analysis. BMC Cancer. 2008; 8:351.

18. Fu Y, Yang W, Wu W, Yan K, Xing BC, Chen MH. Radiofrequency ablation in the management of unresectable intrahepatic cholangiocarcinoma. J Vasc Interv Radiol. 2012; 23:642-49.
19. Zeng ZC, Tang ZY, Fan J, Zhou J, Qin LX, Ye SL, Sun HC, Wang BL, Li D, Wang JH, Zeng MS, Guo W, Tan YS. Consideration of the role of radiotherapy for unresectable intrahepatic cholangiocarcinoma: a retrospective analysis of 75 patients. Cancer J. 2006; 12:113-22.

20. Shinohara ET, Mitra N, Guo M, Metz JM. Radiation therapy is associated with improved survival in the adjuvant and definitive treatment of intrahepatic cholangiocarcinoma. Int J Radiat Oncol Biol Phys. 2008; 72:1495-501.

21. Herfarth KK, Debus J, Lohr F, Bahner ML, Rhein B, Fritz P, Höss A, Schlegel W, Wannenmacher MF. Stereotactic single-dose radiation therapy of liver tumors: results of a phase I/II trial. J Clin Oncol. 2001; 19:164-70.

22. Huertas A, Baumann AS, Saunier-Kubs F, Salleron J, Oldrini G, Croisé-Laurent V, Barraud H, Ayav A, Bronowicki JP, Peiffert D. Stereotactic body radiation therapy as an ablative treatment for inoperable hepatocellular carcinoma. Radiother Oncol. 2015; 115:211-6.

23. Tse RV, Hawkins M, Lockwood G, Kim JJ, Cummings B, Knox J, Sherman M, Dawson LA. Phase I study of individualized stereotactic body radiotherapy for hepatocellular carcinoma and intrahepatic cholangiocarcinoma. J Clin Oncol. 2008; 26:657-64.

24. Kopek N, Holt MI, Hansen AT, Høyer M. Stereotactic body radiotherapy for unresectable cholangiocarcinoma. Radiother Oncol. 2010; 94:47-52.

25. Barney BM, Olivier KR, Miller RC, Haddock MG. Clinical outcomes and toxicity using stereotactic body radiotherapy (SBRT) for advanced cholangiocarcinoma. Radiat Oncol. 2012; 7:67.

26. Mahadevan A, Dagoglu N, Mancias J, Raven K, Khwaja K, Tseng JF, Ng K, Enzinger P, Miksad R, Bullock A, Evenson A. Stereotactic body radiotherapy (SBRT) for intrahepatic and hilar cholangiocarcinoma. J Cancer. 2015; 6:1099-104.

27. van der Voort van Zyp NC, Prévost JB, Hoogeman MS, Praag J, van der Holt B, Levendag PC, van Klaveren RJ, Pattynama P, Nuyttens JJ. Stereotactic radiotherapy with real-time tumor tracking for non-small cell lung cancer: clinical outcome. Radiother Oncol. 2009; 91:296-300.

28. Valle J, Wasan H, Palmer DH, Cunningham D, Anthoney A, Maraveyas A, Madhusudan S, Iveson T, Hughes S, Pereira SP, Roughton M, Bridgewater J. Cisplatin plus gemcitabine versus gemcitabine for biliary tract cancer. N Engl J Med. 2010; 362:1273-81.

29. European Association for the Study of the Liver; European Organisation for Research and Treatment of Cancer. EASL-EORTC clinical practice guidelines: management of hepatocellular carcinoma. J Hepatol. 2012; 56:908-43. 